\title{
DiBOITOS
}

Revista de Comunicación Digital

\section{El uso político de Facebook en la campaña de las Elecciones Locales de 2015 en la ciudad de València}

\section{The political use of Facebook in the 2015 Local Elections campaign in the city of València}

\section{José Gamir-Ríos}

jose.gamir@uv.es

Universitat de València

\section{RESUMEN}

Esta investigación analiza la utilización de Facebook en campaña electoral por parte de los principales candidatos y partidos políticos que se presentaron a las Elecciones Locales de 2015 en la ciudad de València. El trabajo aplica un análisis cuantitativo y de contenido a los 558 mensajes publicados en esta red social por parte de PP, Compromís, Ciudadanos, PSOE y València en Comú, así como de sus respectivos candidatos. Los resultados evidencian un uso unidireccional, con una mayor actividad de los partidos pequeños o emergentes, así como instrumental, centrado en la difusión de informaciones sobre la propia campaña.

\section{ABSTRACT}

This research analyzes the use of Facebook in an electoral campaign by the main candidates and political parties that stood in the Local Elections of 2015 in the city of Valencia. The work applies a quantitative and content analysis to the 558 messages published on this social network by PP, Compromís, Ciudadanos, PSOE and València en Comú, as well as by their respective candidates. The results show a unidirectional use, with a greater activity of small or emerging parties, as well as instrumental, focused on the dissemination of information about the campaign itself.

PALABRAS

CLAVE

comunicación

política

comunicación

interactiva

campaña

electoral

redes sociales

Facebook

\section{KEYWORDS}

political communication

interactive communication

electoral campaign social media

Facebook

\section{Cómo citar este artículo:}

Gamir-Ríos, J. (2021). El uso político de Facebook en la campaña de las Elecciones Locales de 2015 en la ciudad de València. Dígitos. Revista de Comunicación Digital, 7: 211-227. DOI: 10.7203/rd.v1i7.218 


\section{Introducción}

La consolidación de la influencia de Internet en el espacio de debate público y su cada vez más profusa utilización partidista han conducido a la comunicación política a la cuarta fase de su desarrollo (Aagaard, 2016; Bennett \& Pfetsch, 2018; Blumler, 2016; Esser \& Pfetsch, 2020; Magin et al., 2017; Roemmele \& Gibson, 2020). Este nuevo estadio se caracteriza, entre otros factores, por la adquisición de las redes sociales de la condición de principal canal de comunicación política en convivencia con la televisión (Esser \& Pfetsch, 2020); la orientación de las campañas a micronichos de individuos (Roemmele \& Gibson, 2020) cada vez más activos (Esser \& Pfetsch, 2020) mediante el uso estratégico de la tecnología digital y el big data (Calvo et al., 2019; Roemmele \& Gibson, 2020); la utilización de bots automatizados (Calvo et al., 2019) y la modulación de la opinión pública mediante algoritmos (Esser \& Pfetsch, 2020).

El tránsito a esta cuarta etapa es consecuencia, en definitiva, de la adecuación de las prácticas comunicativas de la ciudadanía y de la clase política a las características del actual sistema mediático híbrido (Chadwick, 2013). La consolidación de este nuevo ecosistema ha supuesto la pérdida del monopolio del establecimiento de la agenda pública en campaña electoral por parte de los medios tradicionales (Dader, 2017), hasta el punto de que las redes sociales constituyen ya el nodo central de la comunicación política (Vaccari \& Valeriani, 2016). Precisamente por ello, los partidos han incorporado plenamente los medios digitales a sus estrategias (Casero-Ripollés, 2018; Lilleker et al., 2015).

Aunque Twitter es la red social más estudiada desde el ámbito académico de la comunicación política (Campos-Domínguez, 2017; Jungherr, 2016; Vergeer, 2015), también Facebook ha desempeñado un papel relevante en el advenimiento de este nuevo estadio, al facilitar la relación entre la ciudadanía y la clase política (Giansante, 2015), especialmente relevante en el ámbito local, en el que los atributos percibidos en los candidatos desempeñan un papel significativo en la decisión de voto (Riera Sagrera et al., 2017). De hecho, los políticos que operan en este ámbito valoran más esta red social que los que lo hacen en el estatal (Larsson \& Skogerbø, 2018).

El objetivo de esta investigación es analizar el uso de Facebook de los principales candidatos a la alcaldía de València en la campaña de las Elecciones Locales de 2015, así como por parte de los partidos políticos con los que se presentaron. En concreto, el trabajo analiza las similitudes y diferencias de sus estrategias de uso de esta red social en actividad, multimedialidad, impacto y notoriedad, así como en la composición de sus agendas temáticas.

Dichos comicios se celebraron en el mismo escenario fragmentado y multipartidista que caracterizaba la situación política española desde la celebración de las Elecciones 
al Parlamento Europeo de 2014. Diferentes sondeos coincidían en estimar que el Partido Popular, que gobernaba la ciudad desde 1991, perdería la mayoría absoluta de la que disfrutaba desde 1995, que las federaciones autonómicas del PSOE (PSPVPSOE) y de Izquierda Unida (Esquerra Unida, EU) experimentarían un descenso de voto, y que los entonces emergentes Ciudadanos y Podemos -a través de su candidatura municipalista de València en Comú- obtendrían representación. Todo ello dibujaba un escenario postelectoral abierto, que finalmente se materializó en un gobierno tripartito liderado por Compromís -coalición formada por el nacionalista Bloc, la ecosocialista Iniciativa del Poble Valencià y los ecologistas Verds-Equo- e integrado también por el PSPV-PSOE y València en Comú. Los resultados fueron los siguientes: PP, 10 concejales; Compromís, 9; Ciudadanos, 6; PSPV-PSOE, 5; València en Comú, 3; EU, 0.

\section{El uso político y electoral de Facebook}

Facebook fue creado en febrero de 2004 como una comunidad dirigida a estudiantes universitarios de Harvard y en septiembre de 2006 quedó abierto definitivamente al público general. Sin embargo, su utilización electoral en España no empezó hasta la campaña de las Elecciones Generales de 2008 (Dader, 2009; Peytibi et al., 2008). Las redes sociales sustituyeron a los blogs como principales herramientas digitales de transmisión de las agendas partidistas en las Elecciones Generales de 2011, y su utilización electoral quedó plenamente consolidada en las de 2015. En el caso de esta comunidad virtual, el $22,1 \%$ de los cabezas de lista provinciales de PP y PSOE contó con una página de Facebook en los comicios de 2011 (Gamir Ríos, 2016), porcentaje que se incrementó hasta el 38\% en 2015, teniendo en cuenta también a los de Podemos y Ciudadanos (Gamir Ríos et al., 2017).

Los partidos emplean Facebook para estimular la participación en las elecciones y movilizar el voto (Enli \& Skogerbø, 2013; Stetka et al., 2019), siendo su uso mayor entre las formaciones pequeñas y emergentes (Enli \& Skogerbø, 2013; Magin et al., 2017), pues constituye una herramienta relevante para las opciones que carecen de representación o de impacto mediático (Fenoll \& Cano-Orón, 2019). Además, brinda a los partidos populistas la oportunidad de establecer un vínculo más directo con el electorado (Engesser et al, 2017; Magin et al, 2017). Sin embargo, una mayor actividad no implica necesariamente un mayor engagement (Abejón-Mendoza \& Mayoral-Sánchez, 2017).

La utilización electoral de esta red social se caracteriza por su unidireccionalidad (Enli \& Skogerbø, 2013; Klinger \& Russmann, 2017; López-Meri et al., 2020, Magin et al., 2017; Ross et al., 2015) y su orientación a la difusión de información electoral (Di Bonito, 2014; López-Meri et al., 2020; Marcos García et al., 2020; Magin et al., 2017), como la referida a sus actos de campaña o sus programas (López-Meri et al., 2020), y sin contestar apenas los comentarios de sus usuarios (Di Bonito, 2014; López-Meri et al., 2020). En sus argumentaciones utilizan sobre todo técnicas como la repetición de temas, el apoyo en actitudes preexistentes, la adecuación de temas a públicos concretos y el contagio psíquico, siendo la apelación a los sentimientos, la repetición de temas y la simplificación del mensaje las que generan un mayor número de comentarios (AbejónMendoza y Mayoral-Sánchez, 2017).

Las características dialógicas de las redes sociales (Ross et al., 2015; Lilleker et al., 
2010) no se condicen, así, con el uso que hacen de ellas los partidos, pese a que sus responsables arguyen el diálogo y no solo el marketing como principal motivo de su uso (Enli \& Skogerbø, 2013). De hecho, dicha interacción se produce casi exclusivamente entre los usuarios, con comentarios que suelen caracterizarse por niveles elevados de discrepancia, emociones negativas e insultos (Fenoll \& Cano Orón, 2017; Sampietro \& Valera Ordaz, 2015), siendo mayores cuanto más polarizados están los partidos (Fenoll \& Cano-Orón, 2017).

Los mensajes más atractivos para los seguidores de partidos en la oposición suelen ser los que critican al gobierno; la función más atractiva para los seguidores de partidos en el gobierno, en cambio, es la de la participación y la transmisión de valores, agenda y programa (Marcos García et al., 2020). A su vez, los temas que acumulan más "me gusta" son los relacionados con los resultados electorales, la política social y la organización y el funcionamiento de la campaña. La transmisión de valores e ideología es mayor entre los líderes de partidos emergentes (López-Meri et al., 2020).

Respecto a la multimedialidad, los recursos que suelen obtener más "me gusta" son los que incluyen vídeos y, después, los que incluyen fotografías (Marcos García et al., 2020). Las publicaciones con enlaces también suelen recibir una gran cantidad de "me gusta". En su mayoría se dirigen a páginas de medios de comunicación que tratan sobre el partido (Marcos García et al., 2020) para aumentar su difusión (López-Meri et al., 2020), pero también en ocasiones a redes sociales de otros miembros del partido o a sus páginas web (Di Bonito, 2014).

A partir de todo ello, este trabajo parte de las siguientes preguntas de investigación:

PI1. ¿Cómo utilizaron Facebook en las Elecciones Locales de 2015 los principales candidatos a la Alcaldía de València y los partidos con los que concurrieron, en términos de frecuencia de actualización, multimedialidad, viralidad y notoriedad?

PI2. ¿Cómo se compusieron las agendas temáticas de las formaciones políticas y de sus candidatos en Facebook?

\section{Metodología}

\subsection{Corpus y marco temporal}

La investigación aplica un análisis cuantitativo (PI1) y de contenido (PI2) a las 558 publicaciones difundidas en Facebook durante la campaña de las Elecciones Locales de mayo de 2015 por las cuentas de las agrupaciones del Partido Popular, Compromís, Ciudadanos, PSPV-PSOE y València en Comú en la ciudad de València, así como por sus cabezas de lista -Rita Barberá, Joan Ribó, Fernando Giner, Joan Calabuig y Jordi Peris, respectivamente-.

Las candidaturas analizadas fueron las únicas a las que todas las encuestas publicadas durante los meses previos a los comicios atribuían una intención de voto superior al $5 \%$ necesario para obtener representación en el Ayuntamiento de València, así como las únicas que finalmente lograron dicha representación, con 10, 9, 6, 5 y 3 ediles, respectivamente. 
Tabla 1. Composición del corpus de investigación

\begin{tabular}{|l|l|l|} 
Nombre de la página & URL & Publicaciones \\
\hline Partido Popular Valencia Ciudad & https://www.facebook.com/pages/Partido-Popular- & 0 \\
\hline Valencia-Ciudad/135747903142262 & \\
\hline Rita Barberá Nolla & https://www.facebook.com/RitaBarberaNolla & 16 \\
\hline Coalició Compromís per València & https://www.facebook.com/compromispervalencia & 112 \\
\hline Ciudadanos Vibó & $\underline{\text { https://www.facebook.com/joanribo }}$ & 17 \\
\hline Ciudadano Fernando Giner & $\begin{array}{ll}\text { https://www.facebook.com/ } \\
\text { ciudadanosvalenciaciudad }\end{array}$ & 46 \\
\hline Socialistas Valencia & $\begin{array}{ll}\text { htps://www.facebook.com/ } \\
\text { CiudadanoFernandoGiner }\end{array}$ & 60 \\
\hline Joan Calabuig Rull & $\begin{array}{l}\text { https://www.facebook.com/ } \\
\text { grupomunicipalsocialista.valencia }\end{array}$ & 24 \\
\hline València en Comú & https://www.facebook.com/joan.calabuigrull & 35 \\
\hline Jordi Peris Blanes & https://www.facebook.com/valenciaencomu & 84 \\
\hline & https://www.facebook.com/SoyjordiPeris & 164 \\
\hline
\end{tabular}

Fuente: Elaboración propia.

El periodo analizado comprende los 18 días transcurridos entre el 8/05/2015 y el 25/05/2015, es decir, los 15 días de duración oficial de la campaña de las Elecciones Locales de mayo de 2015, así como la jornada de reflexión, el día de la votación y el día posterior a los comicios. La composición del marco temporal coincide con la contemplada en investigaciones anteriores sobre el uso electoral de las redes sociales en España (Alonso-Muñoz \& Casero Ripollés, 2018; Alonso-Muñoz et al., 2016; Gamir Ríos, 2016; Gamir Ríos et al., 2017; García-Ortega \& Zugasti-Azagra, 2018; López-García, 2016; López García et al., 2015; López García et al., 2016; López-Meri et al., 2017; LópezMeri et al., 2020; Marcos García et al., 2020).

Las páginas analizadas fueron objeto de un seguimiento diario en dos franjas horarias, entre las $14: 00$ y las 15:00 y entre las $23: 00$ y las $24: 00$, con la finalidad de realizar una monitorización continua de su actividad. Ello resultó especialmente conveniente, además, por el cierre de la página Ciudadano Fernando Giner después de las elecciones. Sin embargo, por razones de operatividad, la muestra total fue exportada entre las 00:00 y las 01:00 del 26 de mayo mediante la herramienta online Fanpage Karma.

\subsection{Análisis cuantitativo}

El análisis cuantitativo (P1) ha comparado como variables: 1) la frecuencia diaria de actualización de las cuentas de los partidos y de sus candidatos; 2 ) el carácter multimedia de las publicaciones; 3) el destino de los enlaces; 4) el impacto de los mensajes; y 5) la notoriedad de las cuentas. La primera variable se ha calculado a partir del número total de publicaciones difundidas por cada cuenta, independientemente de su tipo. La segunda, mediante el desglose del número de publicaciones emitidas de cada tipo (texto, enlace, imagen o vídeo). La tercera, a través de la clasificación del destino de las publicaciones (a un medio de comunicación, a la web del partido o del candidato, a Twitter, a Facebook o a otro tipo de destinos). La cuarta, a través del número de "me gusta", comparticiones y comentarios obtenidos. La quinta, por medio del número de seguidores a fecha de inicio y finalización del periodo analizado. 


\subsection{Análisis de contenido}

El análisis de contenido (P2), definido por Krippendorf (1990: 28) como una "técnica de investigación destinada a formular, a partir de ciertos datos, inferencias reproducibles y válidas que puedan aplicarse a su contexto", ha contemplado como variable única la adscripción temática de los mensajes, siguiendo la técnica de análisis categorial temático de contenido (Bardin, 1986: 119). En concreto, el proceso de codificación ha servido para registrar un mínimo de un tema y un máximo de tres por cada ítem recopilado.

Ellibrodecódigossehaestructuradoentresniveles. El primero, comootras investigaciones similares (López García, 2016), ha contemplado las cuatro macrocategorías propuestas por Mazzoleni (2010:210-213) a partir de Patterson: political issues, referidos a cuestiones ideológicas y políticas generales; policy issues, vinculados a propuestas o críticas sectoriales concretas; campaign issues, relacionados con la promoción del partido, la difusión de la agenda de eventos y actos públicos, y los llamamientos a la movilización o la participación; y personal issues, asociado a anécdotas, curiosidades, capacidades, atributos o trayectorias previas de los candidatos. El tercer nivel, inferior, ha servido para desglosar los policy issues en 52 categorías, tras analizar, por un lado, las competencias municipales establecidas en la Ley 7/1985, de 2 de abril, Reguladora de las Bases del Régimen Local; por otro, el organigrama del Ayuntamiento de València a fecha de inicio de la campaña electoral; $y$, por último, los temas presentes en la agenda mediática y política durante los meses previos a la campaña electoral. El segundo nivel, intermedio, ha permitido agrupar dichos 52 temas en ocho bloques mayores, relacionados con las áreas más frecuentes de la gestión municipal o del discurso político o mediático local: 1) hacienda e inversiones; 2) buen gobierno; 3) empleo y promoción económica; 4) urbanismo, grandes proyectos y espacios naturales; 5$)$ movilidad, espacio público y calidad ambiental; 6) seguridad ciudadana; 7) política social; y 8) educación, cultura, fiestas y deporte.

\section{Resultados}

\subsection{Análisis cuantitativo}

\subsubsection{Los partidos}

El partido que comenzó la campaña electoral con un mayor número de seguidores en su página corporativa de Facebook fue Compromís per València, que acumulaba 4.115 "me gusta" a fecha de 8 de mayo de 2015. Le seguían, como constata la Tabla 4, el PSPVPSOE, con 3.696, València en Comú, con 1.466, Ciudadanos, con 1.382, y el PPCV, con 879. El escaso número de seguidores de la página de la agrupación local del PPCV fue consecuencia de la propia estrategia de comunicación digital de la formación, basada en la difusión casi exclusiva de sus mensajes a través de los canales creados con el nombre de su candidata, Rita Barberá. Así, los partidos de centroizquierda e izquierda iniciaron la campaña con un mayor número de seguidores y, con ello, con un mayor número de multiplicadores potenciales de sus mensajes.

Compromís fue la formación que más actualizaciones publicó en la red social durante el periodo analizado, con 112 mensajes, seguida de València en Comú, con 84, Ciudadanos, con 46, y el PSPV-PSOE, con 26. Así, como se muestra en la Tabla 2, la 
coalición valencianista emitió una media de 6,2 mensajes al día, frente a las tasas de 4,7, 2,6 y 1,4 registradas respectivamente por el resto de formaciones mencionadas. El Partido Popular no publicó ningún mensaje en su página corporativa de Facebook durante la campaña electoral.

A su vez, todas las formaciones realizaron más publicaciones con imágenes que con enlaces, con enlaces que con vídeos, y con vídeos que compuestas exclusivamente por texto. El predominio de las imágenes fue absoluto en los casos de Ciudadanos y València en Comú, mientras que Compromís fue la formación que más importancia concedió a los enlaces y el PSPV-PSOE, a los vídeos.

Tabla 2. Actividad en Facebook de los partidos

\begin{tabular}{|l|c|c|c|c|c|c|c|c|c|c|} 
& \multicolumn{3}{|c}{ Publicaciones } & \multicolumn{2}{c}{ Texto } & \multicolumn{2}{c|}{ Enlace } & \multicolumn{2}{c|}{ Imagen } & \multicolumn{4}{c|}{ Vídeo } \\
& N & N/día & N & $\%$ & N & $\%$ & N & $\%$ & N & $\%$ \\
\hline PPCV & $/$ & $/$ & $/$ & $/$ & $/$ & $/$ & $/$ & $/$ & $/$ & $/$ \\
\hline Compromís & 112 & 6,2 & 2 & $1,8 \%$ & 44 & $39,3 \%$ & 55 & $49,1 \%$ & 11 & $9,8 \%$ \\
\hline C'S & 46 & 2,6 & 3 & $6,5 \%$ & 7 & $15,2 \%$ & 30 & $65,2 \%$ & 6 & $13,0 \%$ \\
\hline PSPV-PSOE & 26 & 1,4 & 0 & $0,0 \%$ & 8 & $30,8 \%$ & 10 & $38,5 \%$ & 8 & $30,8 \%$ \\
\hline VLC_Comú & 84 & 4,7 & 0 & $0,0 \%$ & 31 & $36,9 \%$ & 45 & $53,6 \%$ & 8 & $9,5 \%$ \\
\hline
\end{tabular}

Fuente: Elaboración propia.

Por otra parte, en cuanto al destino de los enlaces, todas las formaciones optaron mayoritariamente por incluir vínculos dirigidos a noticias sobre la campaña u otras cuestiones políticas publicadas en cibermedios. Como se observa en la Tabla 3, la presencia relativa de enlaces a medios de comunicación fue especialmente significativa en los casos del PSPV-PSOE, Ciudadanos y València en Comú, cuyos vínculos dirigieron a noticias o entrevistas en un $87,5 \%, 85,7 \%$ y $61,3 \%$ de las ocasiones, respectivamente. Compromís fue, por otra parte, la formación que más utilizó la red social para, a través de enlaces, dirigir a sus usuarios hacia su página web $(22,7 \%)$ o convocarlos a eventos creados en Facebook (43,2\%), seguida por València en Comú (con un 19,4\% en ambos casos).

Tabla 3. Destino de los enlaces publicados en Facebook por los partidos

\begin{tabular}{|c|c|c|c|c|c|c|c|c|c|c|c|}
\hline & \multicolumn{2}{|c|}{ A Medio } & \multicolumn{2}{|c|}{ A web partido } & \multicolumn{2}{|c|}{ A Twitter } & \multicolumn{2}{|c|}{ A Facebook } & \multicolumn{2}{|c|}{ Otro tipo } & Total \\
\hline & $\mathrm{N}$ & $\%$ & $\mathrm{~N}$ & $\%$ & $\mathrm{~N}$ & $\%$ & $\mathrm{~N}$ & $\%$ & $\mathrm{~N}$ & $\%$ & $N$ \\
\hline PPCV & I & 1 & I & I & I & I & I & I & I & I & I \\
\hline Compromís & 14 & $31,8 \%$ & 10 & $22,7 \%$ & 0 & $0,0 \%$ & 19 & $43,2 \%$ & 1 & $2,3 \%$ & 44 \\
\hline C's & 6 & $85,7 \%$ & 0 & $0,0 \%$ & 1 & $14,3 \%$ & 0 & $0,0 \%$ & 0 & $0,0 \%$ & 7 \\
\hline PSPV-PSOE & 7 & $87,5 \%$ & 0 & $0,0 \%$ & 0 & $0,0 \%$ & 1 & $12,5 \%$ & 0 & $0,0 \%$ & 8 \\
\hline VLC_Comú & 19 & $61,3 \%$ & 6 & $19,4 \%$ & 0 & $0,0 \%$ & 6 & $19,4 \%$ & 0 & $0,0 \%$ & 31 \\
\hline
\end{tabular}

Fuente: Elaboración propia.

La coalición valencianista fue la candidatura con mayor tasa de actividad, seguida de València en Comú, Ciudadanos y el PSPV-PSOE. Sin embargo, como se constata en la Tabla 4, València en Comú fue la formación cuyos mensajes alcanzaron una mayor viralidad, al recibir 10.575 "me gusta" (125,9 por publicación), 468 comentarios (5,6 por publicación) y resultar compartidos en 2.160 ocasiones (25,7 por publicación). Le siguen, en las tres categorías, Compromís, Ciudadanos y el PSPV-PSOE. 
Todos los partidos experimentaron un aumento de los seguidores de sus páginas de Facebook durante la campaña electoral, incluido el PPCV -que no tuvo actividad- y a excepción del PSPV-PSOE -que sí la tuvo-. València en Comú registró un aumento de 2.456 seguidores (el 167,53\%); Compromís, de 1.524 (el 37,04\%); Ciudadanos, de 226 (el 16,35\%); y el PPCV, de 24 (el 2,73\%). De esta forma, la viralidad y el crecimiento de las cuentas estuvieron directamente relacionados entre sí y ambos, parcialmente, con la tasa de actividad.

Tabla 4. Notoriedad e impacto en Facebook de los partidos

\begin{tabular}{|c|c|c|c|c|c|c|c|c|c|}
\hline & \multicolumn{3}{|c|}{ Seguidores } & \multicolumn{2}{|c|}{ Me gusta } & \multicolumn{2}{|c|}{ Comentarios } & \multicolumn{2}{|c|}{ Comparticiones } \\
\hline & Inicio & Final & $\%$ & $\mathrm{~N}$ & $\begin{array}{c}\text { Me gusta / } \\
\text { publicación }\end{array}$ & $\mathrm{N}$ & $\begin{array}{c}\text { Comentarios / } \\
\text { publicación }\end{array}$ & $\mathrm{N}$ & $\begin{array}{l}\text { Comparticiones } \\
\text { / Publicación }\end{array}$ \\
\hline PPCV & 879 & 903 & $2,7 \%$ & I & 1 & I & I & l & I \\
\hline Compromís & 4.115 & 5.639 & $37,0 \%$ & 9.956 & 88,9 & 269 & 2,4 & 1.824 & 16,3 \\
\hline C's & 1.382 & 1.608 & $16,4 \%$ & 2.451 & 53,3 & 88 & 1,9 & 294 & 6,4 \\
\hline PSPV-PSOE & 3.696 & 3.694 & $-0,1 \%$ & 1.052 & 43,8 & 20 & 0,8 & 168 & 7,0 \\
\hline VLC_Comú & 1.466 & 3.922 & $167,5 \%$ & 10.575 & 125,9 & 468 & 5,6 & 2.160 & 25,7 \\
\hline
\end{tabular}

Fuente: Elaboración propia.

\subsubsection{Los candidatos}

La candidata que comenzó la campaña electoral con un mayor número de seguidores en Facebook fue Barberá, cuya página oficial acumulaba 14.943 "me gusta" a fecha de 8 de mayo de 2015. Le seguían, como constata la Tabla 7, Ribó, con 3.825, Calabuig, con 3.056, Peris, con 879, y Giner, con 569. La diferencia entre el volumen de seguidores de los candidatos de partidos emergentes y de los formaciones consolidadas es consecuencia lógica de su diferente antigüedad en la red social. Así, mientras la página de Barberá realizó su primera publicación el 19 de julio de 2010, la de Ribó, el 29 de octubre de 2010, y la de Calabuig, el 22 de diciembre de 2014, la página de Giner y el grupo de Peris no fueron creados hasta después de su proclamación como candidatos.

Peris fue el candidato que más actualizaciones publicó en la red social durante el periodo analizado, con 164 mensajes, seguido de Giner, con 60, Calabuig, con 35, Ribó, con 17, y Barberá, con 16. Así, como se muestra en la Tabla 5, el candidato de la formación municipalista emitió una media de 9,1 mensajes al día, frente a las tasas de 3,3, 1,9, 0,9 y 0,9 registradas, respectivamente, por el resto de candidatos. Barberá fue la cabeza de lista que realizó un menor número de publicaciones, pese a que el PPCV centralizó en su página toda su actividad en la red social.

A su vez, todos los candidatos, a excepción de Peris, realizaron más publicaciones con imágenes que con enlaces o vídeos. Como consecuencia de su volumen de actividad, el candidato de València en Comú fue el cabeza de lista que más imágenes, enlaces y vídeos publicó (48, 87 y 25, respectivamente), seguido de Giner $(41,8$ y 10). El predominio de las imágenes fue absoluto en los casos de Ribó (82,4\%), Barberá (75\%), Giner $(68,3 \%)$ y Calabuig $(62,9 \%)$, mientras que Peris le otorgó una relevancia menor $(29,9 \%)$ frente a los enlaces $(53,1 \%)$. La presencia de vídeos ocupó en todos los casos un lugar secundario; y la de publicaciones exclusivamente textuales, residual. Así, todos los candidatos hicieron uso en mayor o menor medida de las posibilidades hipertextuales o multimedia de Facebook. 
Tabla 5. Actividad en Facebook de los candidatos

\begin{tabular}{|l|l|l|l|l|l|l|l|l|l|l|}
\multicolumn{1}{l|}{} & \multicolumn{3}{l}{ Publicaciones } & \multicolumn{2}{c|}{ Texto } & \multicolumn{3}{c|}{ Enlace } & \multicolumn{3}{c|}{ Imagen } \\
\hline & N & N/día & N & $\%$ & N & $\%$ & N & $\%$ & N & $\%$ \\
\hline Barberá & 16 & 0,9 & 1 & $6,3 \%$ & 1 & $6,3 \%$ & 12 & $75,0 \%$ & 2 & $12,5 \%$ \\
\hline Ribó & 17 & 0,9 & 0 & $0,0 \%$ & 0 & $0,0 \%$ & 14 & $82,4 \%$ & 3 & $17,7 \%$ \\
\hline Giner & 60 & 3,3 & 1 & $1,7 \%$ & 8 & $13,3 \%$ & 41 & $68,3 \%$ & 10 & $16,7 \%$ \\
\hline Calabuig & 35 & 1,9 & 0 & $0,0 \%$ & 5 & $14,3 \%$ & 22 & $62,9 \%$ & 8 & $22,9 \%$ \\
\hline Peris & 164 & 9,1 & 4 & $2,4 \%$ & 87 & $53,1 \%$ & 48 & $29,3 \%$ & 25 & $15,2 \%$ \\
\hline
\end{tabular}

Fuente: Elaboración propia.

Por otra parte, en cuanto al destino de los enlaces, todos los candidatos que incluyeron hipervínculos optaron por dirigirlos, mayoritariamente, a noticias sobre la campaña $\mathrm{u}$ otros aspectos políticos publicados en cibermedios. Como se observa en la Tabla 6 , el candidato que más enlaces a noticias incluyó fue Peris (62), seguido de Giner (8) y Calabuig (4). En cambio, sólo Peris compartió de manera significativa vínculos a las páginas web del partido (17) o a la difusión de eventos creados en Facebook para difundir los actos públicos organizados por su candidatura (7). El resto de candidatos desaprovechó dicha posibilidad. Así, la presencia relativa de enlaces a medios de comunicación fue especialmente significativa en los casos de Giner, Calabuig y Peris, cuyos vínculos dirigieron a noticias o entrevistas en el $100 \%$, el $80 \%$ y el $71,3 \%$ de las ocasiones, respectivamente.

Tabla 6. Destino de los enlaces publicados en Facebook por los candidatos

\begin{tabular}{|c|c|c|c|c|c|c|c|c|c|c|c|}
\hline & \multicolumn{2}{|c|}{ A Medio } & \multicolumn{2}{|c|}{ A web partido } & \multicolumn{2}{|c|}{ A Twitter } & \multicolumn{2}{|c|}{ A Facebook } & \multicolumn{2}{|c|}{ Otro tipo } & Total \\
\hline & N & $\%$ & $\mathrm{~N}$ & $\%$ & $\mathrm{~N}$ & $\%$ & $\mathrm{~N}$ & $\%$ & $\mathrm{~N}$ & $\%$ & $\mathrm{~N}$ \\
\hline Barberá & 0 & $0,0 \%$ & 1 & $100,0 \%$ & 0 & $0,0 \%$ & 0 & $0,0 \%$ & 0 & $0,0 \%$ & 1 \\
\hline Ribó & 0 & $0,0 \%$ & 0 & $0,0 \%$ & 0 & $0,0 \%$ & 0 & $0,0 \%$ & 0 & $0,0 \%$ & 0 \\
\hline Giner & 8 & $100,0 \%$ & 0 & $0,0 \%$ & 0 & $0,0 \%$ & 0 & $0,0 \%$ & 0 & $0,0 \%$ & 8 \\
\hline Calabuig & 4 & $80,0 \%$ & 1 & $20,0 \%$ & 0 & $0,0 \%$ & 0 & $0,0 \%$ & 0 & $0,0 \%$ & 5 \\
\hline Peris & 62 & $71,3 \%$ & 17 & $19,5 \%$ & 0 & $0,0 \%$ & 7 & $8,1 \%$ & 1 & $1,2 \%$ & 87 \\
\hline
\end{tabular}

Fuente: Elaboración propia.

Peris fue el candidato con mayor tasa de actividad, seguido de Giner, Calabuig, Ribó y Barberá. Sin embargo, como se constata en la Tabla 7, la tasa de actividad no siempre se correspondió con el volumen absoluto de "me gusta" y comentarios recibidos por las publicaciones, ni por el número de veces en que los contenidos fueron compartidos. Así, Peris fue el candidato que más "me gusta" obtuvo (7.671), en consonancia con su alta actividad, seguido de Barberá (4.267), pese a su escasa frecuencia de actualización, Ribó (3.348), Calabuig (2.309) y Giner (1.442), el candidato que obtuvo menos "me gusta", pese a ser el segundo que más actividad generó.

La tasa de "me gusta" por publicación estuvo encabezada por Barberá $(266,7)$ y Ribó $(196,9)$, los dos candidatos que menos publicaron, seguidos a gran distancia por Calabuig (65), Peris $(46,8)$ y Giner $(24)$, los dos que más lo hicieron. La situación respecto al número de comentarios recibido por publicación fue similar, pues la estadística está de nuevo encabezada por Barberá $(38,1)$ y Ribó $(6,2)$ frente a Peris $(2,3)$ y Giner $(0,6)$. Por su parte, Peris fue el candidato cuyas publicaciones fueron compartidas en más ocasiones (1.844 veces), seguido de Calabuig (477), Ribó (426), Barberá (339) y Giner 
(144). Sin embargo, el promedio de veces en que las publicaciones fueron compartidas está liderado por Ribó $(25,1)$, seguido de Barberá $(21,2)$, Calabuig $(13,6)$, Peris $(11,2)$ y Giner $(2,4)$.

Tabla 7. Notoriedad e impacto en Facebook de los candidatos

\begin{tabular}{|l|c|c|c|c|c|c|c|c|c|} 
& \multicolumn{4}{|c}{ Seguidores } & \multicolumn{2}{c}{ Me gusta } & \multicolumn{2}{c|}{ Comentarios } & \multicolumn{2}{c|}{ Comparticiones } \\
\cline { 2 - 11 } & Inicio & Final & $\%$ & $\mathrm{~N}$ & $\begin{array}{c}\text { Me gusta / } \\
\text { publicación }\end{array}$ & $\mathrm{N}$ & $\begin{array}{c}\text { Comentarios } \\
\text { / publicación }\end{array}$ & $\mathrm{N}$ & $\begin{array}{c}\text { Comparticiones } \\
\text { / publicación }\end{array}$ \\
\hline Barberá & 14.943 & 15.031 & $0,6 \%$ & 4.267 & 266,7 & 610 & 38,1 & 339 & 21,2 \\
\hline Ribó & 3.825 & 4.959 & $29,6 \%$ & 3.348 & 196,9 & 106 & 6,2 & 426 & 25,1 \\
\hline Giner & 569 & 641 & $12,7 \%$ & 1.442 & 24,0 & 33 & 0,6 & 144 & 2,4 \\
\hline Calabuig & 3.056 & 3.120 & $2,1 \%$ & 2.309 & 66,0 & 188 & 5,4 & 477 & 13,6 \\
\hline Peris & 879 & 1.998 & $127,3 \%$ & 7.671 & 46,8 & 378 & 2,3 & 1.844 & 11,2 \\
\hline
\end{tabular}

Fuente: Elaboración propia

De tal forma, es posible establecer que, cuanto mayor fue el número de publicaciones, más posibilidades tuvieron las páginas de recibir "me gusta" o de que sus contenidos fueran compartidos. Sin embargo, el rendimiento viral medio por publicación no estuvo determinado en absoluto por el número total de mensajes publicados, sino que dependió en mayor medida del número de seguidores con el que contaban las páginas a fecha de inicio de la campaña electoral.

Todos los candidatos experimentaron un aumento de los seguidores de sus páginas de Facebook durante la campaña electoral. Peris registró un aumento de 1.119 seguidores (el 127,3\%); Ribó, de 1.134 (el 29,6\%); Barberá, de 88 (el 0,6\%); Giner, de 72 (el 12,6\%); y Calabuig, de 64 (el 2,1\%). Estimamos, sin embargo, que los notables aumentos del número de seguidores de Peris y Ribó fueron consecuencia de factores ajenos a la actividad que desarrollaron en la red social durante la campaña electoral. Consideramos que el incremento experimentado por Peris es atribuible a la reciente apertura de su grupo, que ocasionó una alta transferencia de seguidores desde los espacios corporativos de València en Comú. A su vez, el incremento de Ribó se produjo sobre todo los días 24 y 25 de mayo -su página registraba 3.993 seguidores el día 23, de acuerdo con los datos de FanpageKarma-, con lo que fue consecuencia de los resultados de las elecciones, que, como sucedió, convertían al candidato de Compromís en el probable nuevo alcalde de la ciudad.

\subsection{Análisis de contenido}

\subsubsection{Los partidos}

En lo referente a la composición de la agenda de las páginas corporativas en Facebook por bloques temáticos, todos los partidos priorizaron en mayor o menor medida los asuntos relativos a la campaña electoral-campaign issues-. Compromís fue la formación en cuya agenda más estuvo presente dicho bloque, seguida de Ciudadanos, del PSPVPSOE y de València en Comú. Sin embargo, el peso en la agenda temática fue diferente, pues mientras dicho bloque registró en los dos primeros casos una presencia relativa agregada que sobrepasó el $50 \%$, siendo superior a la suma de las registradas por los demás, en los casos del PSPV-PSOE y de València en Comú se limitó a un tercio de la agenda. En todos los casos, los temas de campaña más presentes en los mensajes publicados en las páginas de Facebook fueron los relacionados con la difusión de los 
eventos y actos públicos y con la realización de llamamientos al voto, de forma implícita o explícita. Las diferencias entre las agendas partidistas radicaron, así, en la importancia otorgada al resto de asuntos.

Tabla 8. Composición de las agendas temáticas de los partidos en Facebook

\begin{tabular}{|l|l|l|l|l|l|}
\multicolumn{1}{l}{} & PP & \multicolumn{3}{l}{ Compromís Ciudadanos } & \multicolumn{3}{l|}{ PSPV-PSOE VLCComú } \\
\hline Policy issues & $0,0 \%$ & $30,1 \%$ & $14,8 \%$ & $32,7 \%$ & $29,4 \%$ \\
\hline Hacienda e inversiones & $0,0 \%$ & $0,0 \%$ & $0,0 \%$ & $0,0 \%$ & $0,0 \%$ \\
\hline Buen gobierno & $0,0 \%$ & $15,5 \%$ & $3,7 \%$ & $12,2 \%$ & $4,4 \%$ \\
\hline Economía y empleo & $0,0 \%$ & $3,3 \%$ & $3,7 \%$ & $6,1 \%$ & $3,3 \%$ \\
\hline Urbanismo y espacios naturales & $0,0 \%$ & $3,3 \%$ & $1,2 \%$ & $0,0 \%$ & $4,4 \%$ \\
\hline Movilidad y calidad ambiental & $0,0 \%$ & $2,8 \%$ & $3,7 \%$ & $4,1 \%$ & $3,3 \%$ \\
\hline Seguridad ciudadana & $0,0 \%$ & $0,0 \%$ & $0,0 \%$ & $0,0 \%$ & $0,0 \%$ \\
\hline Política social & $0,0 \%$ & $3,3 \%$ & $1,2 \%$ & $6,1 \%$ & $9,8 \%$ \\
\hline Educación, cultura y deporte & $0,0 \%$ & $0,9 \%$ & $1,2 \%$ & $4,1 \%$ & $2,2 \%$ \\
\hline Otros & $0,0 \%$ & $0,9 \%$ & $0,0 \%$ & $0,0 \%$ & $2,2 \%$ \\
\hline Political issues & $0,0 \%$ & $4,2 \%$ & $24,7 \%$ & $18,4 \%$ & $28,3 \%$ \\
\hline Campaign issues & $0,0 \%$ & $56,8 \%$ & $50,6 \%$ & $36,7 \%$ & $31,5 \%$ \\
\hline Personal issues & $0,0 \%$ & $8,9 \%$ & $9,9 \%$ & $12,2 \%$ & $10,9 \%$ \\
\hline
\end{tabular}

Fuente: Elaboración propia

En los casos de Compromís, del PSPV-PSOE y de València en Comú, como se muestra en la Tabla 8, el segundo bloque con mayor presencia relativa agregada fue el correspondiente a la política sectorial, relativo a críticas o propuestas concretas; mientras que en el caso de Ciudadanos fue el vinculado a la política general. A su vez, dentro del bloque de policy issues, el área más presente en las agendas de Compromís y del PSPV-PSOE fue la de buen gobierno, con alusiones al despilfarro, la corrupción, la transparencia y el uso partidista de los fondos públicos; mientras que en el caso de València en Comú fue la referida a las políticas sociales. Sólo la agenda del PSPV-PSOE contempló una presencia superior al 5\% de algún área sectorial diferente a la principal: política social y empleo y promoción económica.

Así, las formaciones de izquierda priorizaron las críticas o propuestas en ámbitos concretos, mientras que la candidatura encabezada por Fernando Giner optó por aspectosmás generales, como el eje continuidad-cambioylashipótesis de gobernabilidad y acuerdos postelectorales. Sin embargo, el bloque de political issues también ocupó un lugar destacado en las agendas del PSPV-PSOE y de València en Comú. En el primer caso, para poner en valor la experiencia de gobierno de la candidatura; en el segundo, para subrayar la necesidad de reacción frente al bipartidismo de acuerdo al eje viejanueva política que da origen a la formación y, también, para recordar su vinculación con Podemos.

De todo lo anterior, podemos concluir que las formaciones políticas concedieron mayor importancia a la difusión de las actividades de campaña y al llamamiento al voto de sus posibles electores en perjuicio de las críticas y propuestas sobre áreas de gestión concretas. 


\subsubsection{Los candidatos}

En lo referente a la composición de las agendas de las páginas oficiales de los candidatos en Facebook por bloques temáticos, se produjo una quiebra entre las formaciones en función de su naturaleza: gobierno, oposición consolidada o partidos emergentes. Así, como se refleja en la Tabla 9, mientras las páginas en Facebook de Barberá, Giner y Peris priorizaron los asuntos vinculados a la campaña electoral, a través sobre todo de llamamientos al voto y de la difusión de sus eventos y actos públicos, Ribó y, sobre todo, Calabuig, centraron sus agendas en la realización de críticas o propuestas en relación a áreas concretas de la política sectorial municipal.

Tabla 9. Composición de las agendas temáticas de los candidatos en Facebook

\begin{tabular}{|l|c|c|c|c|c|}
\hline & Barberá & Ribó & Giner & Calabuig & Peris \\
\hline Policy issues & $14,3 \%$ & $45,5 \%$ & $23,2 \%$ & $64,0 \%$ & $23,9 \%$ \\
\hline Hacienda e inversiones & $0,0 \%$ & $0,0 \%$ & $0,0 \%$ & $0,0 \%$ & $1,5 \%$ \\
\hline Buen gobierno & $0,0 \%$ & $20,5 \%$ & $5,4 \%$ & $12,0 \%$ & $6,2 \%$ \\
\hline Economía y empleo & $5,7 \%$ & $9,1 \%$ & $8,9 \%$ & $12,0 \%$ & $0,0 \%$ \\
\hline Urbanismo y espacios naturales & $2,9 \%$ & $6,8 \%$ & $2,7 \%$ & $8,0 \%$ & $6,9 \%$ \\
\hline Movilidad y calidad ambiental & $0,0 \%$ & $2,3 \%$ & $0,9 \%$ & $4,0 \%$ & $2,3 \%$ \\
\hline Seguridad ciudadana & $0,0 \%$ & $0,0 \%$ & $0,0 \%$ & $0,0 \%$ & $0,0 \%$ \\
\hline Política social & $2,9 \%$ & $4,6 \%$ & $2,7 \%$ & $24,0 \%$ & $4,6 \%$ \\
\hline Educación, cultura y deporte & $2,9 \%$ & $2,3 \%$ & $2,7 \%$ & $4,0 \%$ & $1,5 \%$ \\
\hline Otros & $0,0 \%$ & $0,0 \%$ & $0,0 \%$ & $0,0 \%$ & $0,8 \%$ \\
\hline Political issues & $28,6 \%$ & $9,1 \%$ & $18,8 \%$ & $12,0 \%$ & $23,1 \%$ \\
\hline Campaign issues & $42,9 \%$ & $40,9 \%$ & $45,5 \%$ & $20,0 \%$ & $45,4 \%$ \\
\hline Personal issues & $14,3 \%$ & $4,6 \%$ & $12,5 \%$ & $4,0 \%$ & $7,7 \%$ \\
\hline
\end{tabular}

Fuente: Elaboración propia.

El segundo bloque más presente en las agendas de los candidatos que priorizaron los asuntos sectoriales -Ribó y Calabuig- fue el relativo a la campaña electoral, mientras que en el segundo bloque de los candidatos que priorizaron los campaign issues frente a los policy issues se produjo una nueva quiebra. Así, mientras Giner y Peris optaron por conferir un espacio secundario a las políticas sectoriales, Barberá las relegó al tercer lugar, por detrás de los asuntos relativos a la esfera política general. Sin embargo, independientemente de que ocupasen un segundo o tercer lugar en la jerarquía temática de la agenda, los political issues ocuparon más espacio en las agendas de Barberá, Giner y Peris que en las de Ribó y Calabuig. En el caso de Giner, mediante alusiones al modelo de ciudad; en los casos de Barberá y Peris, a través de cuestiones políticas relativas al mismo eje, que la candidata del Partido Popular situó en torno a los polos estabilidad/crecimiento-radicalidad/estancamiento y el candidato de València en Comú en torno al polo nueva-vieja política.

A su vez, el bloque de policy issues experimentó una dispersión generalizada en función de los candidatos. Barberá priorizó la economía; Ribó, el buen gobierno y el empleo; Giner, la economía y el buen gobierno; Calabuig, las políticas sociales, el buen gobierno y el empleo; y Peris, el urbanismo, el buen gobierno y las políticas sociales.

De tal modo, al igual que las páginas de Facebook corporativas de los partidos, las páginas de Barberá, Giner y Peris, candidatos de partidos en el gobierno o emergentes, 
concedieron mayor importancia a la difusión de las actividades de campaña y al llamamiento al voto de sus posibles electores en perjuicio de las críticas y propuestas sobre áreas de gestión concretas. Sin embargo, las páginas de Ribó y Calabuig, partidos consolidados en la oposición, priorizaron los asuntos de política sectorial.

\section{Discusión y conclusiones}

Los partidos políticos y sus candidatos realizaron un uso instrumental de Facebook como herramienta de transmisión del mensaje, pero no como canal de comunicación y fomento de la participación. Las formaciones situadas más a la izquierda del eje ideológico, València en Comú y Compromís, y los candidatos en la oposición (Calabuig y Ribó) o sin representación municipal en el mandato 2011-2015 (Giner y Peris) emplearon la comunidad virtual con mayor intensidad que las formaciones situadas menos a la izquierda o que la candidata oficialista (Barberá). Todo ello está en consonancia con los estudios que apuntan hacia un uso unidireccional de dicha red social (Enli \& Skogerbø, 2013; Klinger \& Russmann, 2017; López-Meri et al., 2020, Magin et al., 2017; Ross et al., 2015) y también con los que detectan una mayor intensidad de uso por parte de las formaciones con menor expectativa de voto (Enli \& Skogerbø, 2013; Magin et al., 2017),

Pese al mayor impacto de los vídeos (Marcos García et al., 2020), las formaciones y los candidatos realizaron más publicaciones con imágenes que con materiales audiovisuales. A su vez, como ya habían detectado otras investigaciones (López-Meri et al., 2020; Marcos García et al., 2020), la mayoría de los enlaces dirigió a páginas de medios de comunicación. También como se ha constatado en trabajos anteriores (AbejónMendoza \& Mayoral-Sánchez, 2017), la tasa de actividad no siempre se correspondió con el volumen de "me gusta" y comentarios recibidos por las publicaciones, ni con el número de veces en que los contenidos fueron compartidos.

Respecto a la composición de las agendas temáticas, todos los partidos y la mayoría de los candidatos priorizaron los asuntos relacionados con la propia campaña electoral, en detrimento de cuestiones sectoriales, ideológicas o personales. Ello está en consonancia con las conclusiones de investigaciones anteriores (Di Bonito, 2014; López-Meri et al., 2020; Marcos García et al., 2020; Magin et al., 2017).

\section{REFERENCIAS}

Aagaard, P. (2016): "The fourth age of political communication: Democratic decay or the rise of phronetic political communication?", en Nordicum Mediterraneum, vol. 11, n 3. https://dx.doi.org/10.33112/nm.11.3.8

Abejón-Mendoza, P. y Mayoral-Sánchez, J. (2017): “Persuasión a través de Facebook de los candidatos en las elecciones generales de 2016 en España", en El Profesional de la Información, vol. 26, nº 5, pp. 928-936. https://doi.org/10.3145/epi.2017.sep.14

Alonso-Muñoz, L. y Casero-Ripollés, A. (2018): "Political agenda on Twitter during the 2016 Spanish elections: Issues, strategies, and users' responses", en Communication \& Society, vol. 3, n 3, pp. 7-23. https://doi.org/10.15581/003.31.3.7-23

Alonso-Muñoz, L., Marcos-García, S. y Casero-Ripollés, A. (2016): “Political leaders in (inter) action: Twitter as a strategic communication tool in electoral campaigns", en Trípodos, vol. 39, pp. 71-90. https://www.raco.cat/index.php/Tripodos/article/view/335035 
Bardin, L. (1986): Análisis de contenido. Madrid: Akal.

Blumler, J. G. (2016): "The fourth age of political communication", en Politiques de Communication, vol. 6, n 1, pp. 19-30. https://doi.org/10.3917/pdc.006.0019

Bennett, W. L. y Pfetsch, B. (2018): "Rethinking political communication in a time of disrupted public spheres", en Journal of Communication, vol. 68, n 2, 243-253. https:// doi.org/10.1093/joc/jqx017

Calvo, D., Campos-Domínguez, E. y Díez-Garrido, M. (2019): “Hacia una campaña computacional: herramientas y estrategias online en las elecciones españolas", en Revista Española de Ciencia Política, vol. 51, pp. 123-154.https://doi.org/10.21308/ recp. 51.05

Campos-Domínguez, E. (2017): “Twitter y la comunicación política”, en El Profesional de la Información, vol. 26, nº 5, pp. 785-793. https://doi.org/10.3145/epi.2017.sep.01

Casero-Ripollés, A. (2018): "Research on political information and social media: Key points and challenges for the future", en El Profesional de la Información, vol. 27, n 5, pp. 964-974. https://doi.org/10.3145/epi.2018.sep.01

Chandwick, A. (2013): The Hybrid Media System. Politics and Power. New York: Oxford University Press.

Dader, J. L. (2009): "Ciberpolítica en los websites de partidos políticos. La experiencia de las elecciones de 2008 en España ante las tendencias transnacionales", en Revista de Sociología e Política, vol. 17, $\mathrm{n}^{\circ}$ 34, pp. 45-62. https://doi.org/10.1590/S0104$\underline{44782009000300005}$

Dader, J. L. (2017): “Campañas políticas 'online': La realidad española frente al horizonte internacional del 'tecnocabildeo'". En Dader, J. L., y Campos, E. (coords.): La búsqueda digital del voto. Cibercampañas Electorales en España 2015-16. Valencia: Tirant lo Blanch, pp. 75-140.

Di Bonito, I. (2014): "El uso de Facebook durante las campañas electorales: Reflexiones sobre las elecciones catalanas de 2010 y 2012", en Revista de la Asociación Española de Investigadores en Comunicación, vol. 1, n 1, pp. 26-34. https://doi.org/10.24137/ raeic.1.1.16

Engesser, S., Ernst, N., Esser, F. y Büchel, F. (2017): “Populism and social media: How politicians spread a fragmented ideology", en Information, Communication \& Society, vol. 20, n 8, pp. 1109-1126.https://doi.org/10.1080/1369118X.2016.1207697

Enli, G. S. y Skogerbø, E. (2013): “Personalized campaigns in party-centred politics: Twitter and Facebook as arenas for political communication", en Information, Communication \& Society, vol. 16, nº 5, pp. 757-774. https://doi.org/10.1080/1369118X.2013.782330

Esser, F.y Pfetsch, B. (2020): “Political Communication”. En Caramani, D. (Ed.): Comparative Politics. Fifth edition. Oxford: Oxford University Press, pp. 336-358.

Fenoll, V. y Cano-Orón, L. (2019): “Communicative differences between emergent and traditional parties: An analysis of facebook posts from Spain's 2015 General Election campaign", en Zer, vol. 24, n 46, pp. 37-51. https://ojs.ehu.eus/index.php/Zer/article/ view/20225 
Gamir Ríos, J. (2016): “Blogs, Facebook y Twitter en las Elecciones Generales de 2011. Estudio cuantitativo del uso de la web 2.0 por parte de los cabezas de lista del PP y del PSOE", en Revista Dígitos, vol. 2, pp. 101-120. https://doi.org/10.7203/rd.v0i2.53

Gamir Ríos, J., Cano Orón, L. y Calvo, D. (2017): “La campaña electoral de 2015 en cifras. La presencia en la blogosfera, Facebook y Twitter de los cabezas de lista provinciales de PP, PSOE, Podemos y Ciudadanos". En López García, G. y Valera Ordaz, L. (Eds.): Pantallas electorales. El discurso de partidos, medios y ciudadanos en la campaña de 2015. Barcelona: Editorial UOC, pp. 41-58.

García-Ortega, C. y Zugasti-Azagra, R. (2018): "Gestión de la campaña de las elecciones generales de 2016 en las cuentas de Twitter de los candidatos: entre la autorreferencialidad y la hibridación mediática". En El Profesional de la Información, vol. 27, nº 6, pp. 1215-1225. https://doi.org/10.3145/epi.2018.nov.05

Giansante, G. (2015): La comunicación política online . Barcelona: Editorial UOC.

Jungherr, A. (2016): "Twitter use in election campaigns: A systematic literature review", en Journal of Information Technology \& Politics, vol. 13, n 1, pp. 72-91. https://doi.org/ 10.1080/19331681.2015.1132401

Klinger, U. y Russmann, U. (2017): “'Beer is more efficient than social media': Political parties and strategic communication in Austrian and Swiss national elections", en Journal of Information Technology \& Politics, vol. 14, n 4, pp. 299-313. https://doi.org/1 0.1080/19331681.2017.1369919

Krippendorff, K. (1990): Metodología de análisis de contenido. Barcelona: Paidós.

Larsson, A. O. y Skogerbø, E. (2018): "Out with the old, in with the new? Perceptions of social (and other) media by local and regional Norwegian politicians", en New media \& Society, vol. 20, nº 1, 219-236. https://doi.org/10.1177/1461444816661549

Lilleker, D. G., Pack, M. y Jackson, N. (2010): “Political parties and web 2.0: The Liberal Democrat Perspective", en Politics, vol. 30, n², pp. 105-112. https://doi.org/10.1111/ j.1467-9256.2010.01373.x

Lilleker, D. G., Tenscher, J. y Štětka, V. (2015): “Towards hypermedia campaigning? Perceptions of new media's importance for campaigning by party strategists in comparative perspective", en Information, Communication \& Society, vol. $18, \mathrm{n}^{\circ} 7$, pp. 747-765. https://doi.org/10.1080/1369118X.2014.993679

López-García, G. (2016): “'Nuevos' y 'viejos' liderazgos: la campaña de las elecciones generales españolas de 2015 en Twitter", en Communication \& Society, vol. 29, n 3, pp. 149-168. https://doi.org/10.15581/003.29.3.149-168

López García, G., Cano Orón, L. y Argilés Martínez, L. (2016): “Circulación de los mensajes y establecimiento de la agenda en Twitter: el caso de las elecciones autonómicas de 2015 en la Comunidad Valenciana", en Trípodos, vol. 39, pp. 163-183. http://www. tripodos.com/index.php/Facultat Comunicacio Blanquerna/article/view/387

López García, G., Gamir Ríos, J., García UII, F., J., Llorca Abad, G., Cano Orón, L. y González Esteban, J. L. (2015): “El debate sobre Europa en Twitter. Discursos y estrategias de los candidatos de las elecciones al Parlamento Europeo de 2014 en España", en Revista 
de Estudios Políticos, vol. 170, pp. 213-246. https://doi.org/10.18042/cepc/rep.170.07

López-Meri, A., Marcos-García, S., y Casero-Ripollés, A. (2017): “What do politicians do on Twitter? Functions and communication strategies in the Spanish electoral campaign of 2016", en El Profesional de la Información, vol. 26, n 5, pp. 795-804. https://doi. org/10.3145/epi.2017.sep.02

López-Meri, A., Marcos-García, S. y Casero-Ripollés, A. (2020): “Estrategias comunicativas en Facebook: Personalización y construcción de comunidad en las elecciones de 2016 en España", en Doxa Comunicación, n 30, pp. 229-248. https://doi.org/10.31921/ doxacom.n30a12

Magin, M., Podschuweit, N., Haßler, J., y Russmann, U. (2017): “Campaigning in the fourth age of political communication. A multi-method study on the use of Facebook by German and Austrian parties in the 2013 national election campaigns", en Information, Communication \& Society, vol. 20, n 11, pp. 1698-1719. https://10.1080/1 369118X.2016.1254269

Marcos García, S., Viounnikoff-Benet, N. y Casero Ripollés, A. (2020): “What is There in a 'Like'? Political Content in Facebook and Instagram in The 2019 Valencian Regional Election", en Debats. Revista de cultura, poder y sociedad, vol. 5, pp. 85-109. https://doi. org/10.28939/iam.debats-en.2020-5

Peytibi, F. X., Rodríguez, J. A., y Gutiérrez-Rubí, A. (2008): “La experiencia de las elecciones generales del 2008", en Revista de Internet, Derecho y Política, nº 7, pp. 26-37.

Riera Sagrera, P., Gómez Martínez, R., Mayoral Díaz-Asensio, J. A., Barberá Aragüena, P. y Montero Gibert, J. R. (2017): “Elecciones municipales en España. La personalización del voto", en Revista Internacional de Sociología, vol. 75, n² 2. http://dx.doi.org/10.3989/ ris.2017.75.2.15.140

Roemmele, A. y Gibson, R. (2020): "Scientific and subversive: The two faces of the fourth era of political campaigning", en New Media \& Society, vol. 22, n 4, pp. 595-610. https:// doi.org/10.1177/1461444819893979

Ross, K., Fountaine, S. y Comrie, M. (2015): “Facing up to Facebook: politicians, publics and the social media(ted) turn in New Zealand", en Media, Culture \& Society, vol. 37, $\mathrm{n}^{\circ}$ 2, pp. 251-269. https://doi.org/10.1177/0163443714557983

Sampietro, A. y Valera Ordaz, L. (2015): “Emotional Politics on Facebook: An Exploratory Study of Podemos' Discourse during the European Election Campaign 2014", en Recerca, $\mathrm{n}^{\circ}$ 17, pp. 61-83. http://dx.doi.org/10.6035/Recerca.2015.17.4

Stetka, V., Surowiec, P. y Mazák, J. (2019): "Facebook as an instrument of election campaigning and voters' engagement: Comparing Czechia and Poland. European", en Journal of Communication, vol. 34, n² 2, pp. 121-141. https://doi. org/10.1177/0267323118810884

Tucker, J. A., Guess, A., Barberá, P., Vaccari, C., Siegel, A., Sanovich, S., Stukal, D. y Nyhan, B. (2018): "Social Media, Political Polarization, and Political Disinformation: A Review of the Scientific Literature", en SSRN Electronic Journal. https://doi.org/10.2139/ ssrn.3144139 
Vaccari, C. y Valeriani, A. (2016): “Party Campaigners or Citizen Campaigners? How Social Media Deepen and Broaden Party-Related Engagement", en The International Journal of Press/Politics, vol. 21, n³, pp. 294-312. https://doi.org/10.1177/1940161216642152

Vergeer, M. (2015): "Twitter and Political Campaigning", en Sociology Compass, vol. 9, $\mathrm{n}^{\circ}$ 9, pp. 745-760. https://doi.org/10.1111/soc4.12294 